\title{
Modeling and Analysis of Proximity Losses in High-Speed Surface Permanent Magnet Machines with Concentrated Windings
}

\author{
Patel B. Reddy \\ patelr@cae.wisc.edu \\ Dept. of Electrical \& Computer Engineering \\ University of Wisconsin-Madison \\ Madison, WI 53706 USA
}

\author{
Theodore. P. Bohn \\ tbohn@anl.gov \\ Energy Systems Division \\ Argonne National Laboratory \\ Argonne, IL 60439-4815 USA
}

\begin{abstract}
Surface permanent magnet (SPM) machines can be designed with fractional slot-concentrated windings (FSCW) to achieve extended speed ranges. High-speed operation can lead to significant levels of proximity losses in the stator windings due to substantial spatial harmonic magnetic fields in the air-gap as well as the high-frequency currents themselves. An integrated analysis tool is presented in this paper to calculate the strandand bundle-level proximity losses in slotted stator conductors without requiring finite element analysis. A combination of analysis techniques, including Laplace equation solutions and conformal mapping, is used to estimate the magnetic field in each stator slot, providing the basis for proximity loss estimation. The match between losses estimated using the analytical model and finite element analysis is very promising.
\end{abstract}

Index terms - AC losses, surface PM machines, high speed, permanent magnet, proximity loss, bundle proximity loss, strand proximity loss, conductor loss, eddy current loss, copper loss.

\section{INTRODUCTION}

Increasing demands for smaller and lighter ac machines in many transportation and industrial applications have intensified efforts to design high-speed ac machines that combine high power density and high efficiency [1]. The resulting increases in excitation frequencies aggravate several loss mechanisms in the machine. Techniques for modeling high-frequency losses in the iron [2] and magnets [3] together with techniques for minimizing these losses have been presented in the literature. However, increased frequencies also escalate the impact of skin and proximity effects in the machine stator windings, raising issues that have not been explored as thoroughly in the literature.

While the concept of skin effect losses has been dealt with thoroughly in the literature [4], traditional models of eddy current losses in conductors have focused on transformers [5] and inductors. Mellor [6] has noted that high ratios of ac to $\mathrm{dc}$ resistances can be exhibited in permanent magnet (PM) machines with fractional-slot concentrated windings (FSCW) due to proximity effects at high frequencies despite the adoption of stranded bundles. Investigations based on finite element (FE) analysis by Mellor and Reddy [7] have investigated the strand- and bundle-level proximity losses of windings in slots that are induced by the high-frequency currents themselves, referred to as armature reaction.

The magnetic field density distribution inside the slot of a machine or an inductor has been shown in literature to be primarily two-dimensional. These models highlight the detrimental impact of fringing flux in the vicinity of the slot opening on the winding ac losses. The calculated field distributions have been shown to be quite accurate for surface PM (SPM) machines[8].

A distinguishing feature of the machines from transformers and inductors is the presence of the rotating flux density distributions in the air-gap contributed by the rotor magnets. The flux distribution inside the slot due to the rotor flux can be estimated analytically using conformal mapping techniques [9]. Conformal mapping techniques have been successfully applied to a variety of slot configurations, with and without tooth-tips. These numerical techniques [10] have been shown to be effective in solving slot models with complex teeth-tip structures.

Previous investigations [6] have shown that ac losses can be high in concentrated winding machines operating at high speeds. When operating under load, the conductors in the slot are exposed to a combination of rotor-induced flux and armature reaction flux. The high-frequency magnetic fields cause both strand and bundle-level proximity losses. The ac losses resulting from the combination of these two flux sources and the two types of proximity losses need to be better understood since it is not obvious a priori what kind of proximity losses dominate in a particular machine.

Models for calculating rotor flux distribution in the air-gap have been presented by Zhu [11], while the flux distribution inside the slots and slotting effects on torque production have been presented by Zarko [9] and Zhu [12], respectively. Additional contributions to the development of 2D slot flux density models caused by armature reaction have been presented by Reddy [8], Lipo [13] and Perry [14]. Analytical models for the prediction of circulating currents in slot conductors have been developed for both strand losses [8] as well as bundle losses [15].

The objective of this paper is to present an integrated analysis tool for predicting the total proximity losses in the slots of a rotating SPM machine with concentrated windings. The model accounts for both strand-level and bundle-level losses caused by either armature reaction or the rotating rotor flux contributed by the magnets. Closed-form analytical techniques are used to predict the flux distribution in the slot, 


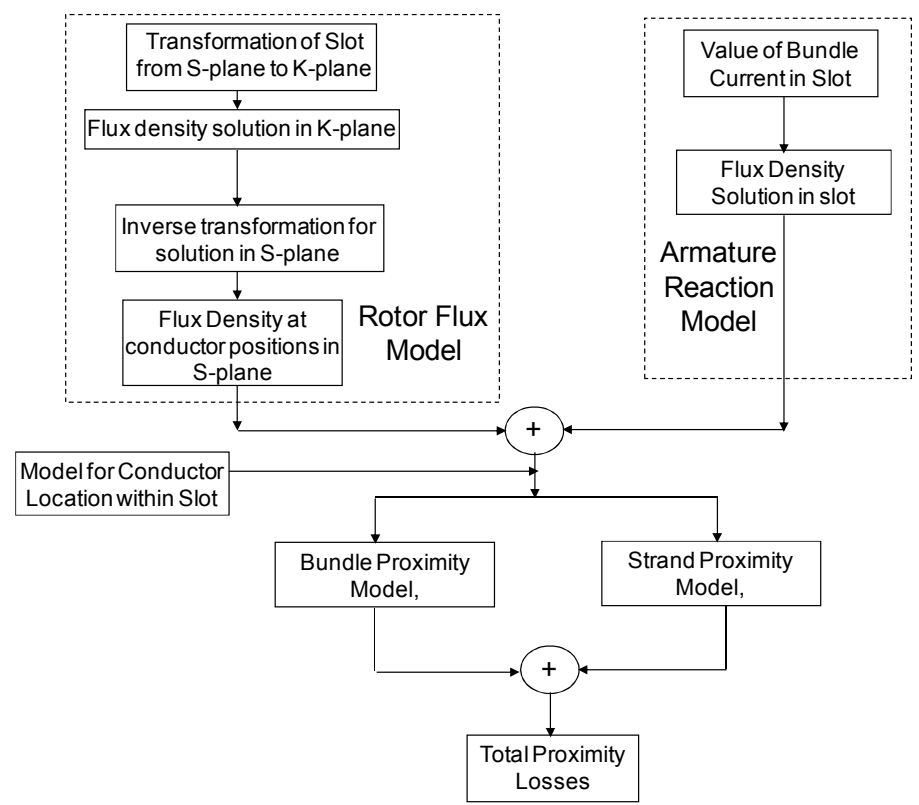

Fig 1: Flow chart for integrated analytical model to predict the total proximity losses in a high-speed SPM machine

including conformal mapping. The flux density solution impinging on each strand and bundle is used to estimate the total proximity losses. Finite element analysis is used to confirm the usefulness to this analytical tool for estimating the total proximity losses. Results from this model show that the proximity loss distribution is different in SPM machines with open-slot and semi-closed stator slot configurations.

\section{ROTOR FLUX DENSITY MODEL}

As noted in Section I, the windings inside the stator slots of SPM machines are exposed to time-varying magnetic fields generated by both armature reaction and the rotating rotor magnet flux. As a result of these high-frequency field components during high-speed operation, circulating currents are created on the surface of the conductors and also among the insulated conductor strands in the same winding turn by the principle of induction.

A comprehensive tool to estimate the magnetic flux density distribution and resulting ac losses as the summation of these two magnetic field sources is presented in the following sections. A flowchart summarizing the structure of this integrated proximity loss calculation model is provided in Fig. 1.

The effects of the rotating rotor flux can be quite different from armature reaction effects depending on the stator and rotor structures. This section presents a model for the proximity losses created by the rotor flux. Subsequent sections describe the incorporation of these losses into a comprehensive ac loss model of a random-wound coil in the slot of a high-speed surface PM machine.

The rotor magnet flux that is responsible for inducing circulating currents in the stator winding is leakage flux that crosses directly between the slot walls or between adjacent stator teeth tips without passing through the stator back iron. The design of the teeth-tips in FSCW machines can have a significant impact on the leakage flux and the resulting circulating currents within the strands and between the different strands of the same winding turn.

The conductors closest to the air-gap between two adjacent teeth tips experience the highest leakage flux and, consequently, the highest circulating currents and ac losses. The leakage flux amplitude drops off rapidly for slot conductors that are further from the slot opening. Predictions of the resulting circulating currents need accurate knowledge of the magnetic flux density inside the slots as well as the conductor distribution throughout the slot area. The flux density distribution caused by armature reaction from currents in the concentrated windings in the slots has been modeled by Reddy [8] and the model is not repeated here.

Closed-form calculation of the flux density distribution within the slot caused by the rotating rotor benefits from the transformation of the slots into simple and smooth structures using conformal mapping using a series of steps summarized in Fig. 4. The work presented here is based on the research done by Zarko [9], considering both open-slot and semiclosed slot configurations. The mapping is based on the semiclosed structure of the slot, and the open-slot structure is considered as a simplified case of the semi-closed structure.

The slot boundary modeled in the physical $S$-plane (Fig. 6) is first transformed into a rectangular shape in the Z-plane (Fig. 7). Using Schwartz-Christoffel mapping techniques, the rectangular slot is next transformed into the upper half of the complex $W$-plane (Fig. 8). Following transformation into the $T$-plane as a rectangular shape (Fig. 9), the final 


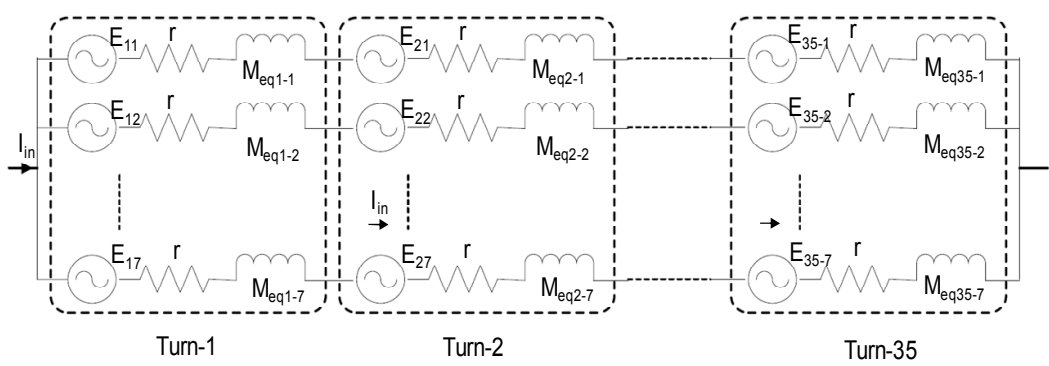

Fig 2: Analytical model of a slot winding consisting of multiple parallel insulated strands that are shorted together at the two ends of the winding for estimation of bundle proximity losses. In this particular example, the winding consists of 35 turns, and each turn includes 7 wire strands in a bundle.

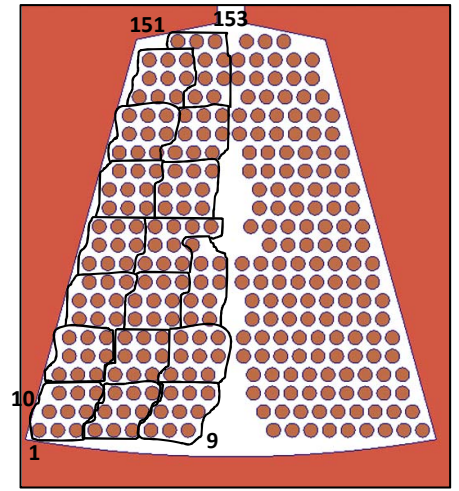

Fig 3: Identification of random-wound bundles gathered from strands in a double-layer winding with nine parallel wire strands in each bundle/turn.
TABLE I: TRANSFORMATIONS FOR CONFORMAL MAPPING OF STATOR SLOT

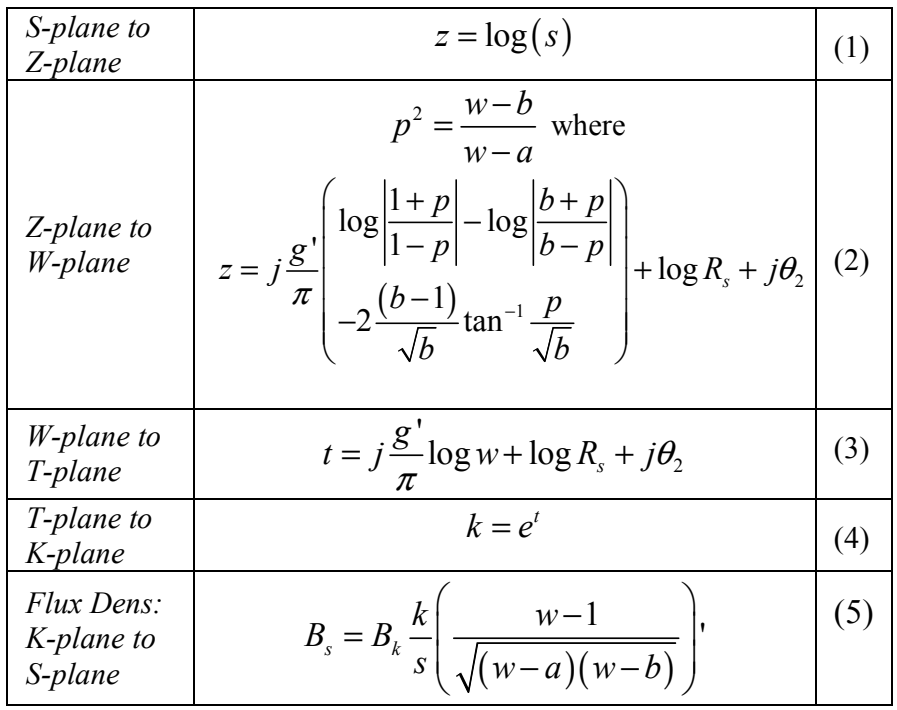

transformation leads to a smooth cylindrical shape in the polar $K$-plane (Fig. 10) that is compatible with a closed-form solution of the flux density distribution. A summary of the key transformation relationships between these planes is provided in Table I.

Equation (5) expresses the flux density in the $S$-plane $\left(B_{s}\right)$ in terms of its $K$-plane value $\left(B_{k}\right)$. Unfortunately, (5) is a not a causal equation and requires a numerical solution that can be time-consuming. Initial causal mapping of the slot ensures a good selection of the initial guess for the solution that accelerates the convergence process. The computation time can be further reduced by the transformation of the mesh grid from the $Z$-plane to the $W$-plane, providing a better initial guess for the solution of (5).

\section{STRAND AND BundLE LosS Models}

Based on the calculated flux density distribution in the slot, the strand-level proximity losses can be calculated and summed for all of the strands in the slot using the following formula:

$$
P_{s t r}=\frac{\pi \omega_{e}^{2} l_{e f f} d^{4} B^{2}}{128 \rho_{c u}}
$$

where $P_{s t r}$ is the strand-level proximity loss in an individual strand, $\omega_{e}$ is the excitation frequency, $l_{e f f}$ is the effective length of the strand, $d$ is the strand diameter, $\rho_{c u}$ is the conductor resistivity, and $B$ is the flux density amplitude at the strand location in the slot.

On the other hand, bundle-level proximity losses need more detailed conductor models. In windings that consist of litz wire or structured composite bundles, it is possible to define organized conductor distributions throughout the slot areas that approximate the actual windings. However, in randomwound stator windings without any transposition (i.e., twisting) of the conductors, it is impractical to define a realistic conductor distribution that is generally applicable.

Instead, assumptions have been developed to govern the bundle model for random-wound winding. First, it should be noted that slots with double-layer concentrated windings have two windings in each slot, as shown in the machine crosssection in Fig 5. Within each of these windings, the conductors in closest proximity are assumed to form a single composite bundle that comprise a winding turn, as illustrated in Fig. 3 for a semi-closed slot. The random winding distribution is preserved since there is no pre-defined conductor distribution inside each bundle/turn.

The model developed for each bundle is shown in Fig. 2 [11]. Each of the strands in the bundle is modeled as a series combination of an induced voltage, resistance, and 


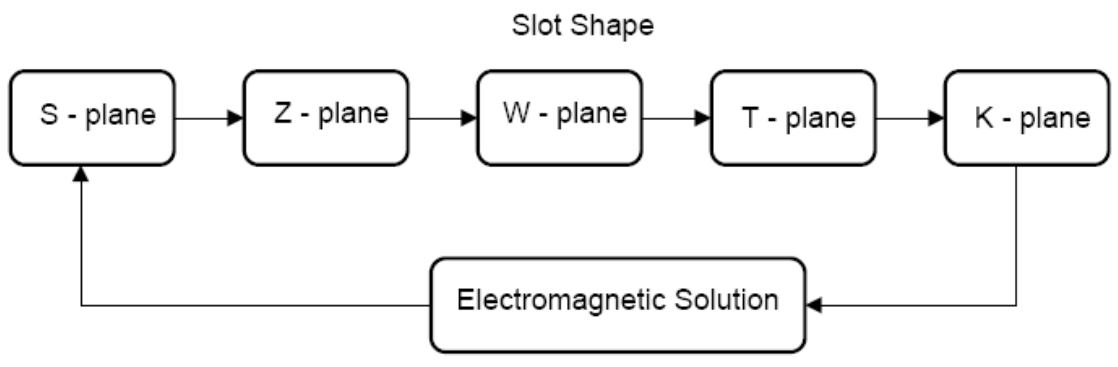

Fig. 4: Calculation step sequence for the application of conformal mapping

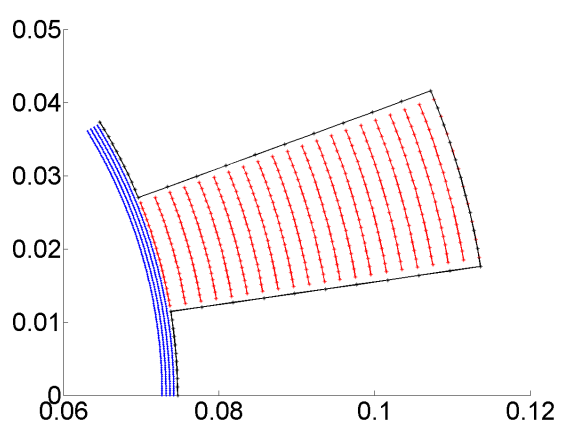

Fig. 6: Slot contours in physical $S$-plane

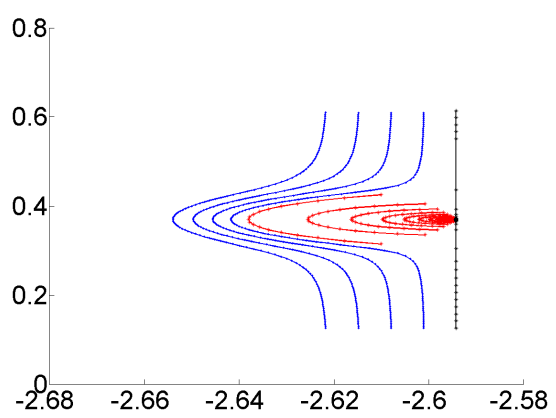

Fig. 9: Corresponding contours in $T$-plane

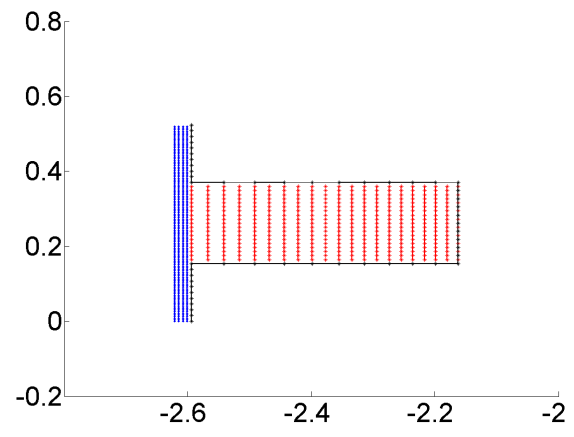

Fig. 7: Corresponding contours in rectangular $Z$-plane

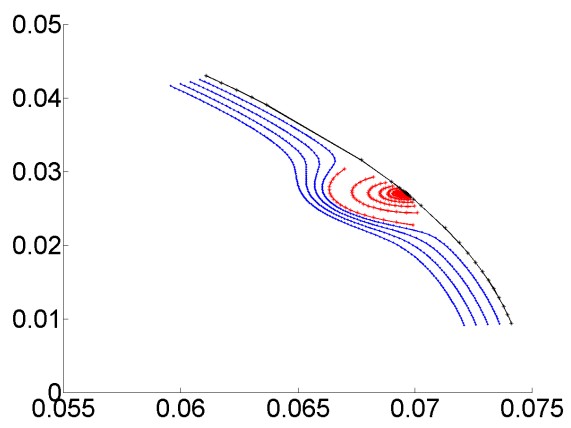

Fig. 10: Corresponding contours in $K$-plane

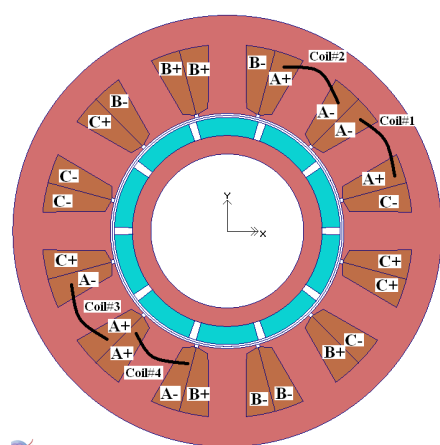

Fig 5: Cross section of SPM machine with fractional-slot concentrated windings.

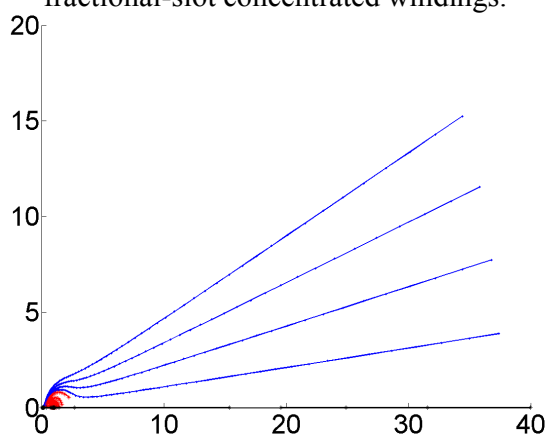

Fig. 8: Corresponding contours in $W$-plane

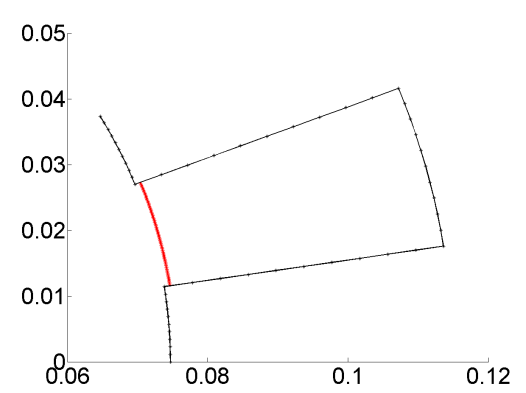

Fig. 11: Path across slot opening without teeth-tips for comparison of analytical and FE flux densities shown in Fig. 12.

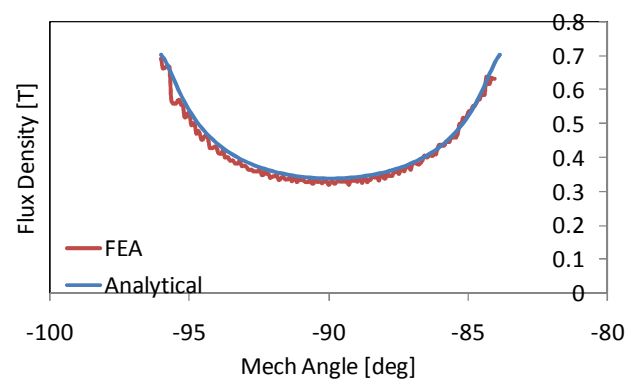

Fig. 12: Comparison of calculated flux density amplitude caused by the rotating rotor magnet flux along the path in Fig. 11 , as predicted by the analytical model and FE analysis.

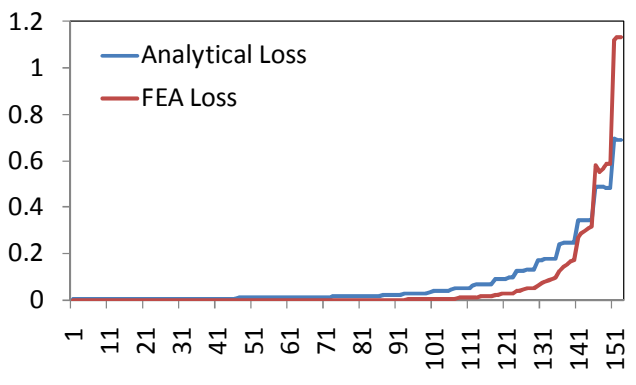

Fig. 13: Comparison of strand-level proximity losses in each slot strand caused by rotating rotor flux, as predicted by the analytical model and FE analysis. 
inductance terms. The induced voltage is a function of the location of the strand within the slot as well as the transposition of the strands in the bundle. Based on the location of the strand, the field density impinging on the strand is estimated using the flux density models referenced in Section I. The conversion from flux density to voltage is made based on the principles of duality between magnetic field and electric field.

The resistance of each strand is determined based on the calculated dc resistance combined with the appropriate skin effect factor. The mutual inductance terms have to be calculated based on the conductor distribution with the slot. Some simplifying assumptions are made at this point, resulting in a decision to include only the mutual inductances between strands in the same bundle.

The model for the complete slot winding is developed by formng a series connections of $k$ of the individual bundle models as indicated in Fig. 3, where $k$ is the number of winding turns in the slot. This model is presented much more completely in Reddy [15] with detailed descriptions of the voltage and circuit models.

Using this complete slot winding model, the circulating currents between different strands within a bundle can be estimated using basic circuit rules. The total bundle loss is then estimated by calculating the circulating currents among the winding strands and the resulting losses dissipated in the strand resistances.

TABLE II: SUMmARY OF KEY FREEDOMCAR AdVANCED Traction MOTOR PERFORMANCE REQUiREMENTs[16]

\begin{tabular}{|l|l|}
\hline \multicolumn{1}{|c|}{ Parameter } & \multicolumn{1}{c|}{ Value } \\
\hline Peak Power @ 2800 r/min & $55 \mathrm{~kW}$ \\
\hline Cont. Power, 2800 to 14,000 r/min & $30 \mathrm{~kW}$ \\
\hline Constant Power Speed Ratio (CPSR) & $5: 1$ \\
\hline Maximum Speed & $14,000 \mathrm{r} / \mathrm{min}$ \\
\hline $\begin{array}{l}\text { Efficiency @ 20\% Rated Torque up } \\
\text { to the max. speed }\end{array}$ & $95 \%$ \\
\hline Machine Active Matl. Power Density & $1.6 \mathrm{~kW} / \mathrm{kg}$ \\
\hline Maximum Phase Current & $400 \mathrm{Arms}$ \\
\hline Max. Peak Line-to-line Back-emf & $600 \mathrm{~V}$ \\
\hline
\end{tabular}

\section{ANALYTICAL RESUltS}

A high-speed FSCW surface PM machine has been designed based on the FreedomCar specifications given in Table II. The specifications call for a high power density motor providing a continuous power of $30 \mathrm{~kW}$ and a peak power of $55 \mathrm{~kW}$ at a corner speed of $2800 \mathrm{r} / \mathrm{min}$. The machine is required to achieve a constant power-to-speed ratio (CPSR) of 5:1 while delivering a continuous power of $30 \mathrm{~kW}$.

A cross-section of the designed machine is shown in Fig 5. This machine has 10 poles and 12 stator slots, making it a member of the $2 / 5$ slot/pole/phase family. The stator is designed with double-layer windings. Each phase winding in a slot contains 17 turns, with each turn consisting of 9 paralleled strands of 16 AWG (American Wire Gauge) insulated copper conductors, for a total of 153 strands in each slot phase winding. There are two slot phase windings in each slot, as indicated in Fig. 5.

As an initial test of the analytical model, the calculated flux density amplitudes near the slot opening including both the armature reaction and rotating rotor flux contributions are compared along an arc path between the two slot walls as shown in Fig. 11. The teeth-tips at the slot opening were removed for this initial analytical test exercise. The predicted flux density amplitudes using the analytical and FE models are overlaid in Fig. 12 demonstrating a very good match.

Validation of key elements of the integrated analytical technique in Fig. 1 is provided by comparing the analytical proximity loss predictions it delivers with FE results. The proximity losses for the open-slot configuration in Fig. 11 have been estimated for the effect rotating rotor flux for operation at $14,000 \mathrm{r} / \mathrm{min}$. The proximity losses estimated using the analytical model for each strand are overlaid with the finite element predictions in Fig. 13, with the numbering scheme shown in Fig 3. The agreement is quite good, with both curves predicting that the eddy current losses are highest in the strands closest to the air-gap. The stepped component in this loss waveform that is particularly apparent in the analytical curve is attributable to the grouping of the wire strands into discrete bundles.

The bundle-level proximity loss results from the armature reaction model have been previously investigated [15] and are not repeated here. Instead, the total strand-level and bundlelevel proximity losses generated by the armature reaction are compared to the corresponding proximity losses contributed by the rotating rotor magnet flux. In addition, the impact of machine load on the total proximity losses is examined under the combined excitation of the rotating rotor magnet flux and armature reaction.

The accuracy of the loss models under different excitation is investigated with the help of four different cases. The first two of the cases examine the effect of the rotor magnet flux on the strand and bundle losses while the second two look at the effect of armature reaction on these same two proximity loss components. The effect of the rotor flux is simulated under open-circuit conditions to eliminate armature reaction, while the effect of stator excitation can be simulated in the absence of the rotor, also referred to as stator-alone conditions.

As an additional fifth case, the total proximity losses in the machine with both a rotating rotor and stator currents are calculated. In the armature reaction cases, the stator carries a current of 100 Apk with a frequency of $1.16 \mathrm{kHz}$ corresponding to its maximum excitation frequency, while the rotor rotation is simulated at $14,000 \mathrm{r} / \mathrm{min}$, its maximum speed. 


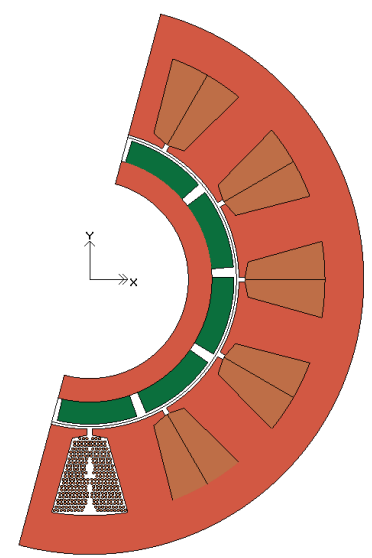

Fig. 14: Cross-section of $55 \mathrm{~kW}$ peak SPM machine with semi-closed slots for $16 \mathrm{AWG}$ case

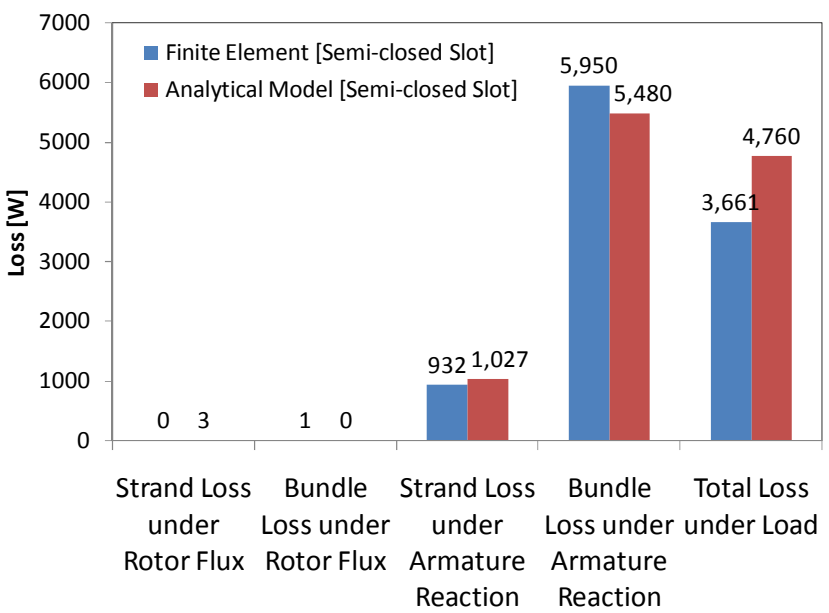

Fig. 16: Comparison of proximity losses for 5 cases predicted by analytical and FE analysis for semi-closed slot structure

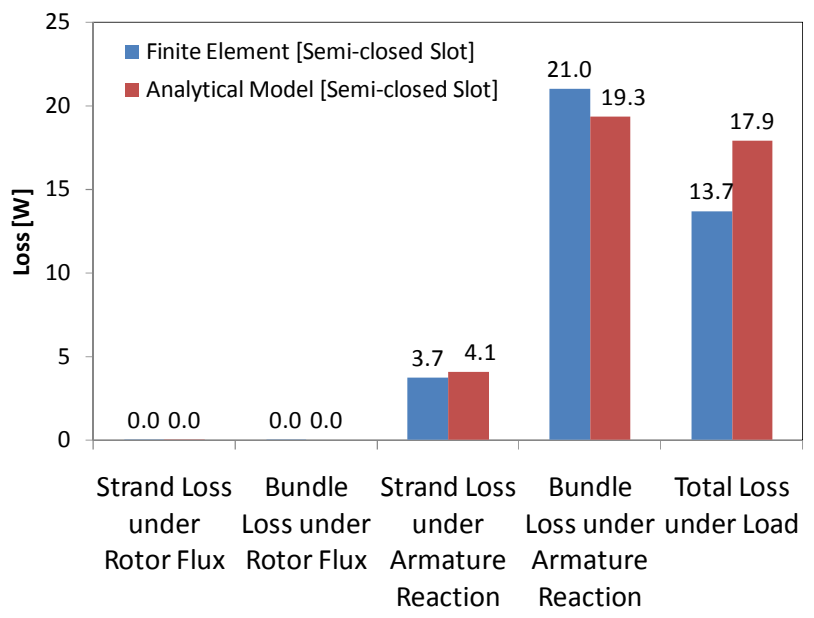

Fig. 18: Comparison of ac to dc loss ratios for 5 cases predicted by analytical and FE analysis for semi-closed structure

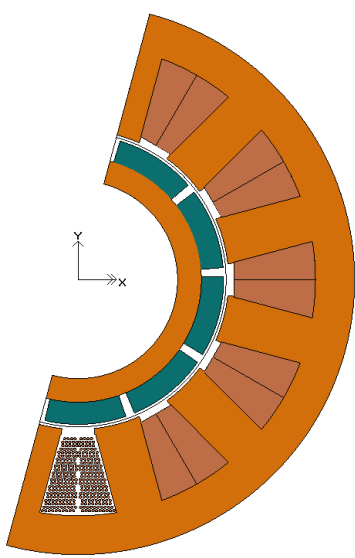

Fig. 15: Cross-section of $55 \mathrm{~kW}$ peak SPM machine with open slots for $16 \mathrm{AWG}$ case

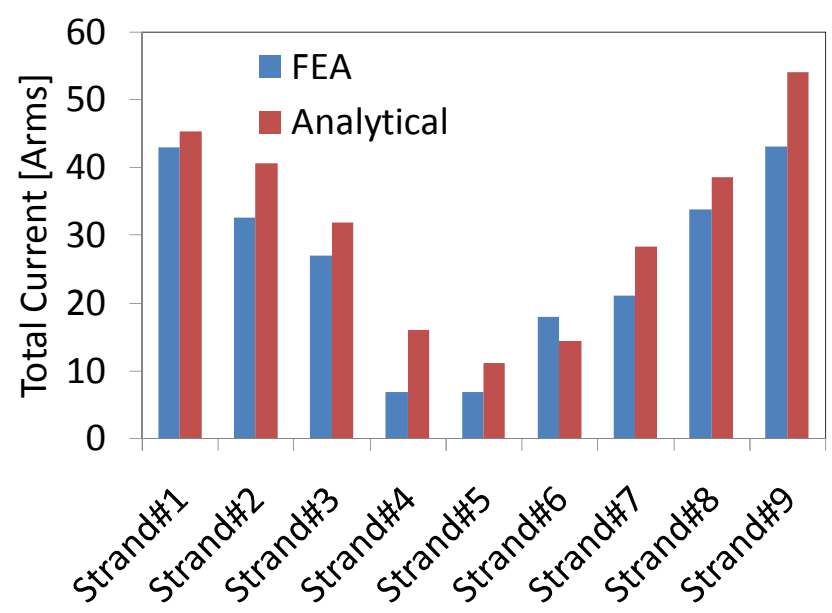

Fig. 17: Comparison of strand currents predicted by 2 models for stator current excitation with semi-closed structure

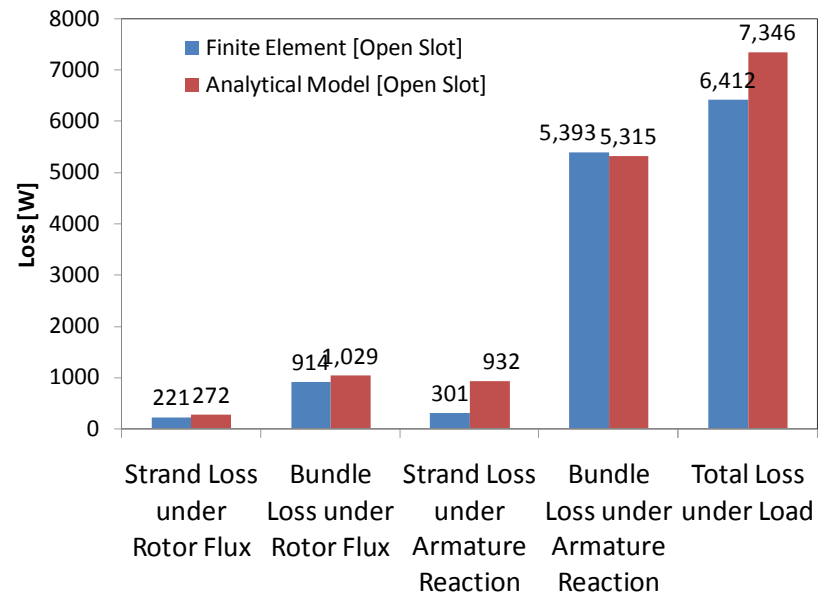

Fig. 19: Comparison of proximity losses for 5 cases predicted by analytical and FE analysis for open-slot structure 


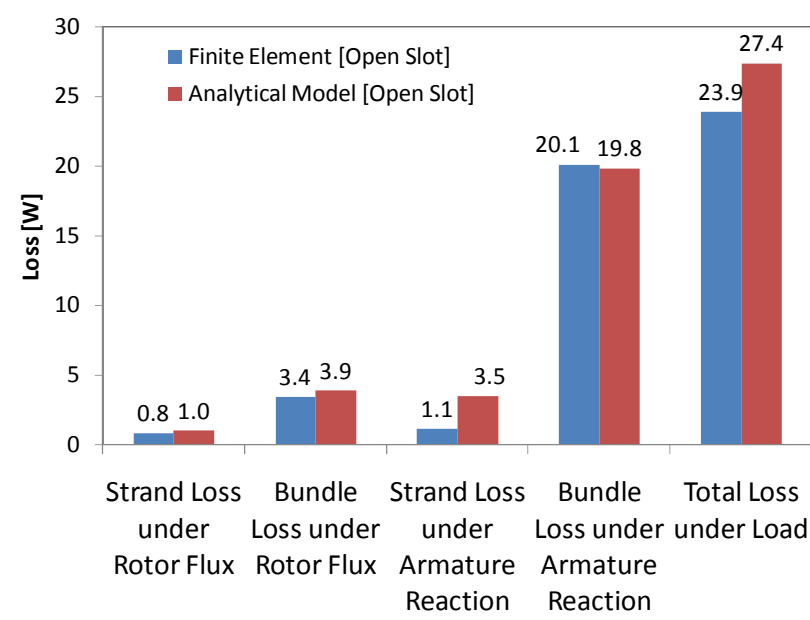

Fig. 20: Comparison of ac to dc loss ratios for 5 cases predicted by analytical and FE models for open-slot structure

As a design variation, two different machine configurations are considered - one with open stator slots, and the other with semi-closed slots (i.e., stator teeth-tips). The rotor structure and the winding distribution are the same in the two designs. The cross-sections of these two designs are shown in Fig. 14 and Fig. 15, respectively.

Fig. 16 shows a comparison of the predicted strand and bundle proximity losses under the different excitation conditions described above for the stator with semi-closed slots. For the first case of rotor rotation and without stator current excitation, i.e. open-circuit conditions, the timevarying rotor flux causes both strand- and bundle-level circulating currents and proximity losses in the stator windings. The calculated losses using the analytical model and FE analysis are very low compared to the other proximity loss components and barely register in Fig. 16. For the semiclosed slot structure, the teeth-tips serve to shield the conductors from the rotor field, suppressing the generation of strand and bundle proximity losses.

The next two pairs of bars in Fig. 16 show the corresponding calculated strand and bundle proximity losses caused by the stator excitation in the absence of the rotor. The dc and skin effect ac losses in the windings have been removed in order to isolate the proximity loss components. The armature reaction produces fringing fields around the slot opening as well as slot leakage crossing the slot that combine to produce a significant amount of strand and bundle proximity losses. The FE-predicted strand losses in the semiclosed structure are shown to be approx. $932 \mathrm{~W}$ in the whole machine, and this result agrees well with the analytical model prediction.

Armature reaction is also responsible for generating 5950 $\mathrm{W}$ of bundle-level proximity losses in the machine, and this value is matched within $8 \%$ by the analytical model results, as shown in Fig. 16. Fig. 17 shows the predicted current amplitude in each of the 9 parallel conductor strands that comprise each winding turn. The lack of transposition of the strands in the winding bundle gives rise to circulating currents among the parallel strands that are shorted at the two ends of the winding. As indicated in Fig. 17, the amplitudes of the circulating currents caused by the armature reaction can grow large, causing the amplitudes of the individual strand currents to differ by ratios exceeding 5:1. The agreement between the strand current predictions of the analytical model and FE analysis is quite good.

The final proximity loss predictions included in Fig. 16 is for the combined excitation case of flowing stator current and rotor rotation while the machine is producing greater than rated torque. The total magnetic field appearing in the slots is formed by the combined effects of the armature reaction and the rotating rotor magnets. All sources of ac losses are reflected in the FE results.

It is interesting to note that the predicted proximity losses due to the combined stator and rotor excitation effects are lower than the case of armature reaction excitation alone. To understand this counterintuitive result, it must be recognized that the magnetic field in the stator teeth and teeth-tips produced by the armature reaction can either aid or counteract the field contributed by the rotor magnets. For the operating condition considered here, the two field contributions counteract each other, reducing the level of magnetic saturation in the teeth-tips. This allows the teeth-tips to shunt more of the magnetic flux between the adjacent teeth-tips without generating as much fringing flux near the slot opening where it can produce significant amounts of proximity losses in the stator conductors.

The ratios of the ac to dc conductor losses for the semiclosed slot structure are shown in Fig. 18 for the same set of conditions as in Fig. 16. This ratio is negligible under opencircuit conditions with only the rotating rotor flux. However, in the presence of the stator excitation, the ratio of ac to dc losses is seen to reach values of $\sim 20: 1$ for stator currents of $100 \mathrm{Apk}$ at $1.16 \mathrm{kHz}$. The ac losses are proportional to the square of the frequency and become quite high at frequencies beyond $1 \mathrm{kHz}$ in this machine. The ac to dc loss ratio decreases under the loaded operating condition with both rotor and stator excitation due to same reason cited above involving reduced saturation in the teeth-tips.

The same excitation cases that were examined above for the semi-closed stator slot configuration have been investigated for the open-slot counterpart configuration. For the open-slot stator with only the rotating rotor flux, the conductors are more exposed to circulating rotor flux in the absence of the teeth-tips, and this increases the strand and bundle proximity losses in the conductors. As shown in Fig. 19 , the predicted strand losses under rotor excitation can approach $300 \mathrm{~W}$ in the complete machine (rated for a power of $30 \mathrm{~kW}$ ), and the bundle losses are at least three times higher.

Considering next the case of stator excitation in the absence of the rotor, the magnetic field produced by armature reaction 
generates a significant amount of leakage flux that penetrates the stator conductors. The predicted strand losses are somewhat lower than for the semi-closed slot configuration (Fig. 16), but the predicted bundle losses in the vicinity of 6 $\mathrm{kW}$ are much higher than the strand losses and comparable to the bundle loss values predicted for the semi-closed slot case. The agreement between loss results predicted using the two analytical approaches is generally very good in Fig. 19.

Under loaded conditions with both the rotating rotor magnet flux and the stator current, the predicted total proximity losses in the machine exceed $6.4 \mathrm{~kW}$ as shown in Fig. 19. Unlike the previous semi-closed stator configuration, the predicted total proximity losses for the loaded machine exceed the calculated losses for the rotating rotor and armature reaction cases alone. In the absence of teeth-tips, the air-gap flux components contributed by the rotating rotor and armature reaction combine to increase the slot leakage flux over the values with each excitation alone, resulting in a net increase in the proximity losses.

The calculated ratios of ac to dc copper losses for the openslot configuration are shown in Fig. 20. It is notable that the predicted ratio of ac to dc losses for the loaded machine case reaches a value of approx. 25 for the open-slot stator configuration, highlighting the elevated winding exposure to leakage flux and resulting proximity losses created by removal of the teeth-tips.

\section{CONCLUSIONS}

This paper presents an integrated analytical tool for estimating the total proximity losses in the stator windings of surface PM machines with concentrated windings that are operated at high rotor speeds. Both strand- and bundle-level proximity losses created by the rotating rotor flux and armature reaction are combined into the same analytical model. The much higher computational speed of this analytical model compared to FE analysis makes it practical to incorporate this model into machine design programs that identify optimum designs by iteratively evaluating very large numbers of candidate designs using Monte Carlo or genetic optimization algorithms.

Confidence in the validity of this analytical tool has been raised using the design details of a $30 \mathrm{~kW}$ (cont.) highperformance surface PM machine that was designed to meet demanding FreedomCar specifications. Comparisons of predicted proximity losses during maximum speed operation at 14,000 r/min have yielded very good agreement between results from the analytical model and $\mathrm{FE}$ analysis for individual loss components and combined totals. This favorable performance of the integrated loss model has been demonstrated for stators both with and without teeth-tips.

The availability of this integrated proximity loss model offers promising prospects for improving the designs of highspeed ac machines in demanding applications such as electric traction for which efficiency takes on special importance as a critical design criterion.

\section{ACKNOWLEDGEMENTS}

The support of the Wisconsin Electric Machines and Power Electronics Consortium (WEMPEC) is gratefully acknowledged. The authors also wish to thank Mr. Hiroyuki Sano of the JSOL Corp. for their generous technical support in using the JMAG finite element software.

\section{REFERENCES}

1. EL-Refaie, A.M., "High Speed Operation of Permanent Magnet Machines", PhD Thesis, Univ. of Wisconsin- Madison, (2005).

2. EL-Refaie, A.M., T.M. Jahns, and J.W. McKeever, "Modified Vector Control Algorithm for Increasing Partial-Load Efficiency of FractionalSlot Concentrated Winding Surface PM Machines", in Rec. of 2006 IEEE Ind. Appl. Soc. Ann. Mtg, Oct. 2006, vol. 1, pgs. 50-57.

3. Atallah, K., D. Howe, P.H. Mellor, and D.A. Stone, "Rotor Loss in Permanent-Magnet Brushless AC Machines", IEEE Trans. Industry Applications, Nov/Dec 2000, vol. 36(6), pgs. 1612-1618.

4. Snelling, E.C., "Soft Ferrites - Properties and Applications", 1988 (Second Edition).

5. Dowell, P.L., "Effects of eddy currents in transformer windings", Proc. IEE, Aug 1966, vol. 113, No. 8, pgs. 1387-1394.

6. Mellor, P.H., R. Wrobel, and N. McNeill, "Investigation of Proximity Losses in a High Speed Brushless Permanent Magnet Motor", in Rec. of 2006 IEEE Ind. Appl. Soc. Ann. Mtg,, Oct 2006, vol. 3, pgs. 1514-1518.

7. Reddy, P.B., T.M. Jahns, and T.P. Bohn, "Transposition Effects on Bundle Proximity Losses in High-Speed PM Machines", in Proc. of 2009 IEEE Energy Conversion Congress and Exposition, Sept 2009.

8. Reddy, P.B., Z.Q. Zhu, S.H. Han, and T.M. Jahns, "Strand-level Proximity Losses in PM Machines Designed for High-Speed Operation", in Proc. of 38th Intl Conf. on Elec. Mach., Sept 2008.

9. Zarko, D., D. Ban, and T.A. Lipo, "Analytical Calculation of Magnetic Field Distribution in the Slotted Air Gap of a Surface Permanent-Magnet Motor Using Complex Relative Air-Gap Permeance", IEEE Trans. on Magnetics, 2006, vol. 42, No.7, pgs. 1828-1837.

10. Vamaraju, S.R.M., "Improvements in Numerical Techniques for Conformal Transformation with Particular Reference to Electromagnetic Fields", IEEE Trans on Magnetics, Jul 1978, vol. 14, No. 4, pgs. 233240.

11. Zhu, Z.Q., D. Howe, E. Bolte, and B. Ackermann, Instantaneous Magnetic Field Distribution in Brushless Permanent Magnet dc Motors, Part I: Open-Circuit Field, IEEE Trans. Magnetics, January 1993, vol. 29(1), pgs. 124-135.

12. Zhu, Z.Q., D. Howe, E. Bolte, and B. Ackermann, Instantaneous Magnetic Field Distribution in Brushless Permanent Magnet dc Motors, Part III: Effect of Stator Slotting, IEEE Trans. Magnetics, January 1993, vol. 29(1), pgs. 143-151.

13. Lipo, T.A., "Introduction to AC Machine Design": Wisconsin Power Electronics Research Center, University of Wisconsin-Madison. 2004.

14. Perry, M.P., "Multiple Layer Series Connected Winding Design for Minimum Losses", IEEE Trans Power Apparatus and Systems, January 1979, vol. 98, pgs. 116-123.

15. Reddy, P.B. and T.M. Jahns, "Analysis of Bundle Proximity Losses in High-Speed Machines" in Proc. of 2010 International Power Electronics Conference, June 2010.

16. U.S. Dept. of Energy, "Development of Power Electronics and Electric Motor Technology for plug-in Hybrid Electric Vehicles, Internal Combustion Engine Hybrid Electric Vehicles and Fuel Cell Vehicle Traction Drive Applications", 2006, pgs. 9-10. 